\title{
A Research on Utilization Plan Applying the Characteristics of the Silver Generation on Smartphone Acceptance Factors
}

\author{
WonWhoi Huh ${ }^{1}$, YoungShin $\mathrm{Han}^{2}$, JongSik Lee ${ }^{3}$ and JungGil Cho ${ }^{4}$ \\ ${ }^{1}$ Division of Multimedia, Sungkyul University \\ ${ }^{2}$ Divi. of Liberal Arts and Teaching, Sungkyul University \\ ${ }^{3}$ Department of Computer and Information Engineering, Inha University \\ ${ }^{4}$ Division of Computer Engineering, Sungkyul University \\ ${ }^{1}$ wonwhoi@naver.com, ${ }^{2}$ hanys@skku.edu, ${ }^{3}$ jslee@inha.ac.kr, \\ ${ }^{4}$ innocom@dreamwiz.com • \\ Abstract
}

The worldwide trend of aging is highlighting the importante of the silver generation as a major consumer group for various industries. In particular, the wecessity of mobile services for the silver generation in the IT industry is inoreasing. The purpose of this research is to develop a smart phone utilization plan by analyzing the needs of developing mobile services applying the characteristics of the silkergeneration bn smart phones and by studying the smart phone acceptance factors.

Keywords: Silver Generation, Smart Phône, Mobile Usability, Mobile Device Technology

\section{Introduction}

The global population is aging rapildy and especially the aging rate of Korea is most rapid in the world. Due to this woldyide aging phenomenon industries targeting the silver generation are increasingly, receiving attention. With the development of infocommunications technology cellphones have become a daily necessity that cannot be separated from our dailyliyes. Cellphones are developing with technological changes, leading to higher performance, miniaturization, lightening in weight; and these developments demand more complicated and difficult interaction abilities. However, generally the aged silver generations have trouble in using small-sized multimedia devices such as cellphones or PMPs due to the physical and psychological limitations followed by aging. Moreover it is predicted that the silver generation will also become a major consumer group for small-sized electronic devices in the IT related industries. Therefore, the necessity of mobile services for the silyer generation is increasing. However currently inadequate amount of research related to smart phone services for the silver generation has been achieved domestically, and research related to smartphone mobile services has been focused mainly on developing user interface design. In fact, it is difficult to find researches related to using needs analysis and development strategies, which are fundamental parts to consider in order to develop mobile services. In this sense, research on the smart phone utilization plan for the silver generation is greatly required. Smart phones targeting the silver generation should be polished and classy while considering the hobbies and emotions of the users rather than focusing on the inconveniences followed by their declining physical functions such as deteriorating eyesight. 


\section{Research Objectives and Methods}

The purpose of this research is to propose a utilization plan for smartphones by applying factors that decide the acceptance of smartphones based on the understanding of the silver generation's emotions, values and experiences. Every time with the advent of new media, researches regarding acceptance of new media attempted to explain the utilization process of the new media and the media environment. From an academic perspective, the importance of this research is in that it studied and analyzed systematically to analyze the acceptance factors processes of a new media, smartphones. The majority of existing researches contemplated the characteristics of the media from a functional perspective, however in this research the characteristics of the silver generation was analyzed as passive users from a interaction perspective. In this sense, this research has academic significance as it has atrempted to discuss about a new research system based on a cognitive process using eflection and reference (Constantiou, 2009).

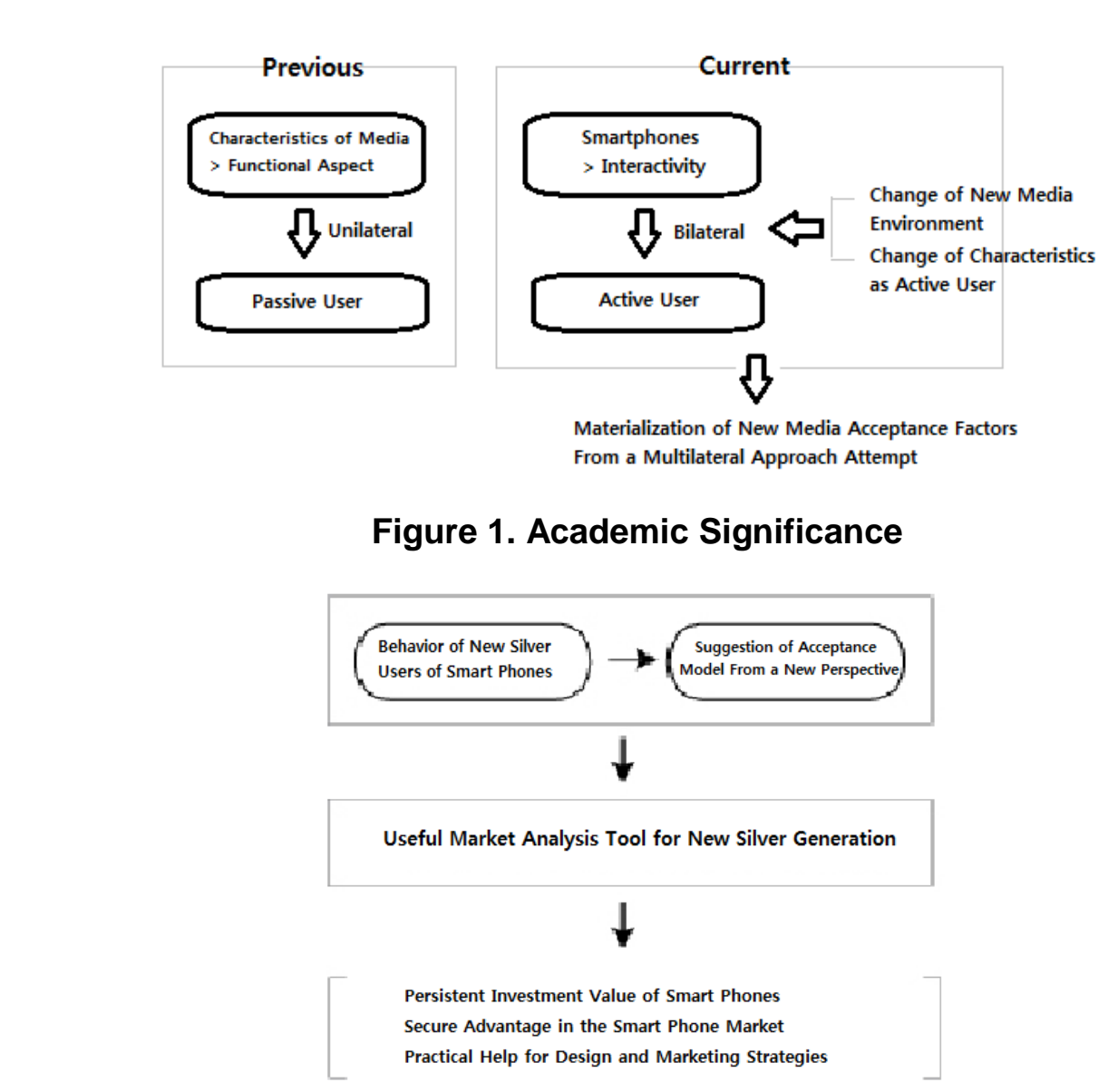

Figure 2. Empirical Significance

\section{Smartphone Utilization Plan Based on the Characteristics of the Silver Generation}

Current mobile devices have various functions integrated in a small-sized device in order to satisfy the various demands of consumers, making it difficult to operate and utilize 
(Lindholm and Keinonen, 2003). Therefore it is very important to understand the motives, the drives and the behaviors of the smart phone users when consuming media and their level of satisfaction. Katz 1959 focused on, from a consumer's position, what people do with mass media rather than what mass media does to the people. People of the modern society try to satisfy their desires through media. Therefore this research suggests a utilization plan through technological integration for the silver generation pursuing emotional satisfaction, which can be achieved by applying the individual values on smart phones. Especially through in-depth interviews, the fundamental process that derives emotional values, situated deep within the inner side of certain targets of the new silver generation, is examined.

Smartphones are examples of two representative technological tendencies: extension of function and minimization of device. A small-sized screen and limited number of buttons, etc., present hardship in performance of function, the importance of usability and utitity, which allow users to utilize products effectively, is therefore emphasized (Lindholm and Keinonen, 2003). As the development of technology and assimilation of product quality make the distinctions between products meaningless, consumers' emotional factor acts as an important directive decision making factor.

Firstly, the concept diagram Figure 3 depicts the integration of contents existing inside the mobile device, the outer appearance of smart phone, and applications producing mobile contents while also showing value creation of the silver generation through integrated technology, design and emotional values. Based on the wireless network integrated with user emotions, mutual relation can be formed and users share their contents and thoughts. Especially, contents connected to the wireless network can be shared with anyone, anywhere and anytime through mobile devices, and reproduced into a form suitable to the respective characteristics of different media.

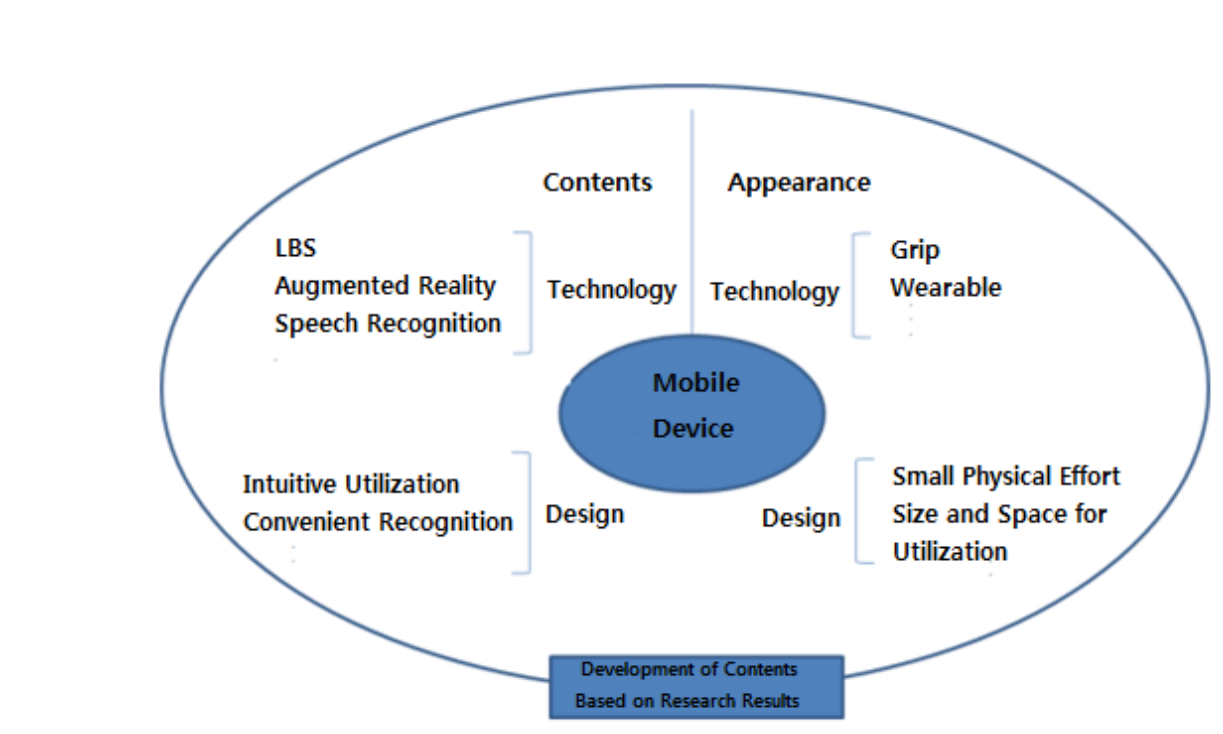

Figure 3. Contents Development Concept Diagram

Based on the contents development concept mentioned above, when categorizing the characteristics of the established development environment of the new product, which integrated the contents of mobile devices, the universal design for external appearance and the emotional values of the new silver generation, there are 3 perspectives to consider. 


\section{(1) The Relationship between Contents and Appearance of Mobile Devices}

The newly developed design can be divided into two parts: the contents as the inner part of the mobile device and the appearance as the outer part. In fact, external designs such as the appearance of mobile devices influence convenience and satisfaction of users. Companies put great efforts to develop new designs for mobile devices. This creates added value and identity of the device. Likewise, new mobile device corresponding to the emotions of the silver generation should be produced. The newly created design will become a point of contact with the information society for the silver generation and a bridge connecting generations.

The inner contents, as the combination of technology with the form of application, should be composed of a form that can maximize the significance and values of the silver generdtion, based on the technological characteristics of mobile device. Moreover, the inner contents must have the function of supplying a platform for collective intelligence by making resources open, sharing and participating convenient for all silver generation users. Under these circumstances, the newly formed collective intelligence will create new/product value.

\section{Increase of Usability}

The newly developed design realizes real time network information sharing by applying mobile device technology that allows real time-network acgess. Majority of users in the modern society have communication and tecord storage devices such as mobile phones or digital cameras, but in reality it is two times more diffecult for the silver generation than the young generation to use these devices Therefore, by planning based on universal design, this digital core technology aims to increase usability.

Network products such as newry developed PDP, image viewer, digital accessories can create combined product vatue by integrating with contents created by users participation through digital devices connected to the wireless internet environment. Such products are one of the items for creating profit in the new business area. This will not only increase value with concepts of entertaiment and ownership but also continuously maintain and develop the new market of the IT industry through persistent development of items.

\section{(3) Mobile Networb of the New Products}

The new produets utilize the digital application system that allows network access anytime and anywhere which is one of the key features of effective information exchange for mobiles. Information that can be shared through the advanced technology offered by mobile devices can be exchanged in various forms such as text messages, images, and video files, and at the same time real time uploading and downloading will become possible. The optimal condition for maximizing the emotional values of the silver generation can be achieved with the integration of mobile devices. Such mobile device technology will lead to developing various applications and this will become a new business item applicable anywhere. 


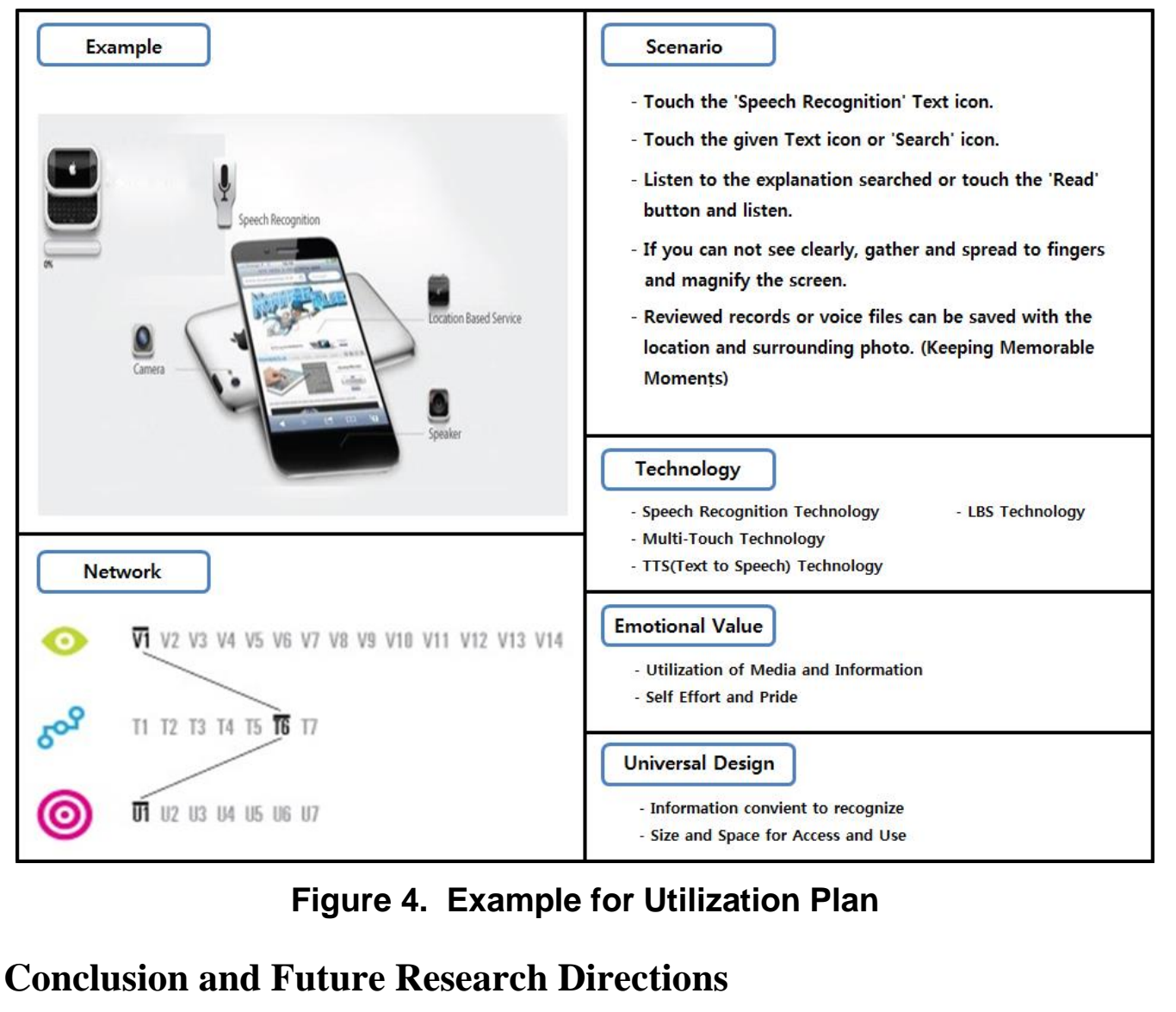

The ultimate aim of this research development is to understand the silver generation's needs and make-improvements, Which can enhance their participation and satisfaction by reflecting the silver'generation's emotional values while gratifying the trend of mobile devices. At the same tina, by creating a new business model appropriate for the new paradigm of mobile devices (smart phones), this research will help companies to expand new business areas. Also with the purpose of increasing mobile usability by reflecting the emotional value of the silver generation, this research is significant in that it suggests an integrated method combining inner contents, universal design, mobile device technology, and emotional values of the new silver generation. In future studies it is necessary to go one step further frem the suggested integrated method to reflect reviews and feedbacks through direct participation of the silver generation. In order to fulfill this, the number of silver generation smar phone users must increase in advance and by analyzing many participants the characteristics of the silver generation with various lifestyles can be subdivided into details. With the purpose of enhancing mobile usability by reflecting the emotional values of the silver generation, this research will emerge as an exemplary smartphone utilization plan for the silver generation, as it suggests not only the internal contents and external designs but also an integrated method connecting mobile device technology and emotional values of the silver generation.

\section{References}

[1] B. Kim, H. Lee, K. Heo and Y. Ko, "Silver Care Service Utilizing Mobile Devices", Journal of the Institute of Internet, Broadcasting and Communication, vol. 9, no. 3, (2009), pp. 225-232. 
[2] H. C. Kim, , “Product' becomes 'Art' and Captivates Consumers”, Journal of Korea Broadcast Advertising Corporation's Advertisement Information, vol. 320, (2007), pp. 22-25.

[3] K. Y. Lee, "Social Activity of Korean the Elderly, Andragogy Today: Interdisciplinary", Journal of Adult and Continuing Education, vol. 5, no. 2, (2002), pp. 1-22.

[4] S. Y. Lee, "Study on Variables for Mental Stability of the Aged When Using Information and Communication Instruments", Seoul Venture University, (2010).

[5] J. H. Lee, "Mobile Silver Care Service Based on GPS and SMS", Journal of the Korean Institute of Communications and Information Sciences", vol. 34, no. 12, (2009), pp. 355-362.

[6] J. Y. Oh, "Research on User Value of Mobile Phone Design Factors", Ewha Womans University, (2009).

[7] J. H. Lee, "Mobile Service Development Strategy for the Silver generation", Korean Design Forum, vol. 27, (2010), pp. 337-346.

[8] Lee and Hwang, "A Study on Teenagers' Mobile Phone Use Motives and Addiction - Focusing øn Primary”, Middle and High School Students in Seoul and Gyeonggi Province, Korean Journal of Broadcasting yol. 23, no. 5, (2009), pp. 296-338.

[9] K. H. Song, "Study on Niche Market of Cable TV", Korean Society for Journalism and Communication Studies, vol. 42, no. 3, (1998), pp. 5-23975.

[10] J. H. Song, "Conceptualization of Mobile Digital Divide and Suggestions for Settlement", KADO Issue Report, vol. 1, (2004), no. 7, pp. 1-43.

[11] M. S. Choi, "Study on the Impact of Individual Innovativeness Social Influence, User Interface Factors on Smart Phone Acceptance: Focusing on Extended Technology Acceptance Model", Ewha Womans University, (2011).

[12] H. Choi, S. Oh, K. Han and H. Moon, "Interface Pesign of Digital(On-hne) TV for Silver Generation Convenience", Korea Digital Design, vol. 8, no. 1, (2008), pp. 381-398.

[13] W. W. Huh, "The Influence of Emotional Valu Factors on the New Silver Generation's Acceptance of Digital media", Seoul National University of Science and Technology (2012).

[14] Bayus, "The Consumer Durable Replacement Buyer", Journal of Marketing, (1991), pp. 42-51.

[15] I. D. Constantiou, "Telematics and Informatics", vol. 26, (2009), pp. 270-281.

[16] A. Maslow, "The Farther Reaches of Human Nature", Viking, New York, NY (1971).

[17] Lindholm, Keinonen and H. Kiljander, "Mobile Usability", McGraw-Hill 75 (2003).

[18] Plant, "On the mobile, the effects of mobile teltphones on social and individual life", Report made for Motorola (2002).

[19] Protokid, Mobile kids, A European adolesdent mobile phone user survey (2000).

[20] M. Kim, S. Kim, Y.Kim E. Song andy. Lee, "Understanding of the Industry for the Elderly", Kimoonsa (2011).

[21] W. Huh, Y. Han 1. Lee and J. Cho, A Research on Utilization Plan Applying the Smartphone Acceptance Factors of th Silver Generation", SERSC, vol. 43, 158-161, (2013) December 11-13; Jeju Island, Korea.

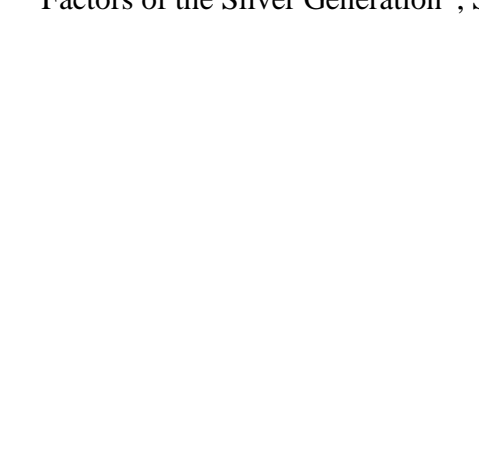

